\title{
Perbandingan Antara Metode RUP dan Prototype Dalam Aplikasi Penerimaan Siswa Baru Berbasis Web
}

\author{
Farid Mubarok*1, Harliana ${ }^{2}$, Ijah Hadijah ${ }^{3}$ \\ 1,2,3 Teknik Informatika STIKOM Poltek Cirebon \\ E-mail: *1'mubarokvarid@gmail.com, ${ }^{2}$ harliana.merdiharto@gmail.com, \\ 3vivaramadhani@gmail.com
}

\begin{abstract}
Abstrak
The system of registration and enrollment process that is still using the manual method, the manual registration form hereinafter be recapitulated in the ledger by the committee PSB into the computer. Because the number of applicants who pretty much and continues to grow, so that the input process, data processing and delivery of information resulting from the admission requires substantial time. To overcome this, they invented a new student enrollment applications to facilitate web-based committee in the data processing new admissions and delivery of information with analytical comparison of two methods of software development is the method of RUP and Prototype. In order to obtain a new student registration system with software development method is more accurate in making new student enrollment applications and webbased delivery of desired results in the form of information and reports quickly.
\end{abstract}

Kata Kunci - Aplikasi, Web, RUP, Prototype

\begin{abstract}
The system of registration and enrollment process that is still using the manual method, the manual registration form hereinafter be recapitulated in the ledger by the committee PSB into the computer. Because the number of applicants who pretty much and continues to grow, so that the input process, data processing and delivery of information resulting from the admission requires substantial time. To overcome this, they invented a new student enrollment applications to facilitate web-based committee in the data processing new admissions and delivery of information with analytical comparison of two methods of software development is the method of RUP and Prototype. In order to obtain a new student registration system with software development method is more accurate in making new student enrollment applications and webbased delivery of desired results in the form of information and reports quickly.
\end{abstract}

Keywords - Application, Web, RUP, Prototype

\section{PENDAHULUAN}

Penginputan data siswa baru pada tahun ajaran baru adalah hal yang tidak dapat dihindari, karena hal tersebut merupakan salah satu tahapan yang harus dilalui sebelum terselenggaranya kegiatan belajar mengajar, proses pendaftaran yang masih menggunakan cara manual yaitu dengan kertas formulir pendaftaran kemudian dicatat pada buku buku besar. Hal ini menyulitkan bagi calon siswa yang jauh dari sekolah yang ingin mendaftar dan mengetahui hasil penerimaan secara cepat karena hasil penerimaan masih diinformasikan melalui papan pengumuman.

Data siswa yang tersimpan dalam bentuk data arsip sering kali hilang, Hal ini menyebabkan terhambatnya panitia dalam mengolah dan mencari data siswa yang diterima untuk melakukan pendaftaran ulang. Dalam kegiatan pelaksanaan sistem penerimaan siswa baru dibutuhkan sebuah sistem berbasis web yang dibutuhkan dunia kerja sekarang untuk 
meminimalkan waktu dan kinerja. Oleh karena itu penulis mencoba mengembangkan suatu sistem penerimaan siswa baru secara online.

Pendekatan kasus pada peneletian ini menggunakan metode deskriptif, yaitu suatu metode dengan tujuan untuk membuat gambaran secara sistematis, faktual dan akurat mengenai fakta-fakta dan sifat-sifat pada suatu objek penelitian tertentu. Adapun teknik pengumpulan data yang digunakan adalah observasi dan wawancara. Pengembangan sistem ini, penulis menggunakan dua metode pengembangan sistem yaitu RUP dan Prototype guna untuk mengetahui keakuratan sistem yang akan dibangun sehingga dapat membawa hasil dalam mencapai tujuan dengan teknik pengumpulan data yang digunakan, yaitu wawancara dan observasi. dan rancangan program menggunakan bahasa pemrograman PHP dengan database MySql. Dari pemaparan latar belakang masalah diatas maka penulis akan melakukan penelitian dengan judul "Perbandingan Antara Relational Unified Process (RUP) dan Prototype Dalam Aplikasi Penerimaan Siswa Baru berbasis Web“.

\section{METODE PENELITIAN}

Metode pengembangan dilakukan dengan beracuan pada rekayasa perangkat lunak. Metodologi kerja yang digunakan dalam pengembangan aplikasi perangkat lunak ini adalah relational unified process (rup) dan prototype.

\subsection{Relational Unified Process}

Relational Unified Process (RUP) adalah pendekatan perangkat lunak yang dilakukan berulang-ulang (iterative), fokus pada arsitektur (architecture-centric), lebih diarahkan berdasarkan penggunaan kasus (use case driven). RUP merupakan proses rekayasa perangkat lunak dengan pendefinisian yang lebih baik (well defined) dan penstrukturan yang baik (well structured). RUP menyediakan pendefinisian yang baik untuk alur hidup proyek perangkat lunak. RUP adalah sebuah produk proses perangkat lunak yang dikembangkan oleh Rational Software yang diakuisisi oleh IBM di bulan Febuaari 2003.

Proses pengulangan/iteratif pada RUP secara global dapat dlihat sebagai berikut:

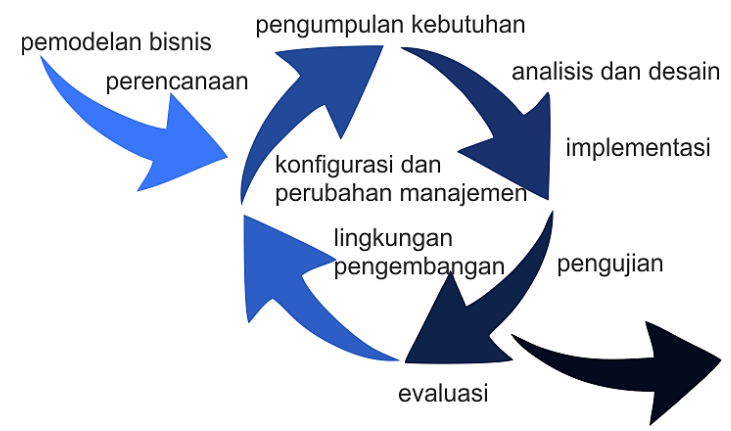

Gambar 1. Proses iteratif RUP

RUP memiliki 4 tahap atau fase yang dapat dilakukan pula secara iteratif. Berikut adalah penjelasan untuk setiap fase RUP:

1. Inception (permulaan)

Tahap ini lebih pada memodelkan proses bisnis yang dibutuhkan (business modeling) dan mendefinisikan kebutuhan akan sistem yang akan dibuat (requirements).

2. Elaboration (perluasaan/perencanaan)

Tahap ini lebih difokuskan pada perencanaan arsitektur sistem. Tahap ini juga dapat mendeteksi apakah arsitektur sistem yang diinginkan dapat dibuat atau tidak. Mendeteksi resiko yang mungkin terjadi dari arsitektur yang dibuat. Tahap ini lebih pada analisis dan desain sistem serta implementasi sistem yang fokus pada purwarupa sistem (prototype). 
3. Contruction (kontruksi)

Tahap ini fokus pada pengembangan komponen dan fitur-fitur sistem. Tahapan ini lebih pada implementasi dan pengujian sistem yang fokus pada implementasi perangkat lunak pada kode program. Tahap ini menghasilkan produk perangkat lunak dimana menjadi syarat dari Initial Operational Capability Milestone atau batas/tonggak kemampuan operasional awal.

4. Transition (transisi)

Tahap ini lebih pada deployment atau instalasi sistem agar dapat dimengerti oleh user. Tahap ini menghasilkan produk perangkat lunak dimana menjadi syarat dari Initial Operational Capability Milestone atau batas/tonggak kemampuan operasional awal. Aktifitas pada tahap ini termasuk pada pelatihan user, pemeliharaan dan pengujian sistem apakah sudah memenuhi harapan user [1].

\subsection{Prototype}

Prototype merupakan salah satu metode pengembangan perangat lunak yang banyak digunakan. Dengan metode prototyping ini pengembang dan pelanggan dapat saling berinteraksi selama proses pembuatan sistem. Prototyping, dimulai dengan pengumpulan kebutuhan pelanggan terhadap perangkat lunak yang akan dibuat, mendefinisikan objektif keseluruhan dari software, mengidentifikasikan segala kebutuhan, kemudian dilakukan "perangcangan kilat" yang difokuskan pada penyajian aspek yang diperlukan agar pelanggan lebih terbayang dengan apa yang sebenarnya diinginkan. Berikut adalah gambar dari model prototype:

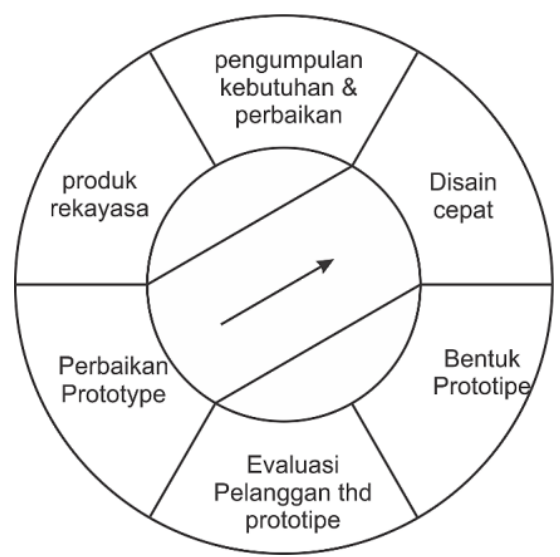

Gambar 2. Ilustrasi Model Prototype

Berikut adalah penjelasan untuk setiap fase Prototype:

a. Pengumpulan Kebutuhan dan perbaikan

Menetapkan segala kebutuhan untuk pembangunan perangkat lunak.

b. Disain cepat

Tahap penerjemahan dari keperluan atau data yang telah dianalisis ke dalam bentuk yang mudah dimengerti oleh user.

c. Bentuk Prototype

Menerjemahkan data yang telah dirancang ke dalam bahasa pemrograman (Program contoh atau setengah jadi ).

d. Evaluasi Pelanggan Terhadap Prototype

Program yang sudah jadi diuji oleh pelanggan, dan bila ada kekurangan pada program bisa ditambahkan.

e. Perbaikan Prototype

Perbaikan program yang sudah jadi, sesuai dengan kebutuhan konsumen. Kemudian dibuat program kembali dan dievaluasi oleh konsumen sampai semua kebutuhan user terpenuhi.

f. Produk Rekayasa

Program yang sudah jadi dan seluruh kebutuhan user sudah terpenuhi. [2] 


\subsection{Aplikasi}

Aplikasi adalah seperangkat intruksi khusus dalam komputer yang dirancang agar kita dapat menyelesaikan tugas-tugas tertentu. Sebagai contoh, aplikasi Word Processing adalah sebuah aplikasi yang diperuntukkan membuat dokumen tertulis, aplikasi web browser adalah aplikasi yang diperuntukkan untuk mencari sesuatu dan menampilkan halaman web. [3]

\subsection{Web}

Menurut Hidayat, (2010:2), Website atau situs dapat diartikan sebagai kumpulan halaman-halaman yang digunakan untuk menampilkan informasi teks, gambar diam atau gerak, animasi, suara, dan atau gabungan dari semuanya, baik yang bersifat statis maupun dinamis yang membentuk satu rangkaian bangunan yang saling terkait, yang masing-masing dihubungkan dengan jaringan-jaringan halaman. [4]

Menurut Simarmata, (2010:51), "Web dapat diartikan sebagai alat untuk menciptakan sistem informasi global yang mudah berdasarkan pada hiperteks". [5]

\section{HASIL DAN PEMBAHASAN}

Perbandingan metode pengembangan perangkat lunak RUP dan Prototype dalam membangun aplikasi penerimaan siswa baru berbasis web, maka desain sistem yang digunakan adalah sebagai berikut:

\subsection{Desain Sistem Menggunakan Metode Relational Unified Precess (RUP)}

\subsubsection{Usecase Diagram}

Use case terdiri atas diagram use case dan actor. Actor merepresentasikan orang yang akan mengoperasikan atau orang yang berinteraksi dengan system aplikasi. Use case merepresentasikan operasi-operasi yang dilakukan oleh actor. Adapun use case di bawah ini adalah sistem pendaftaran siswa baru.

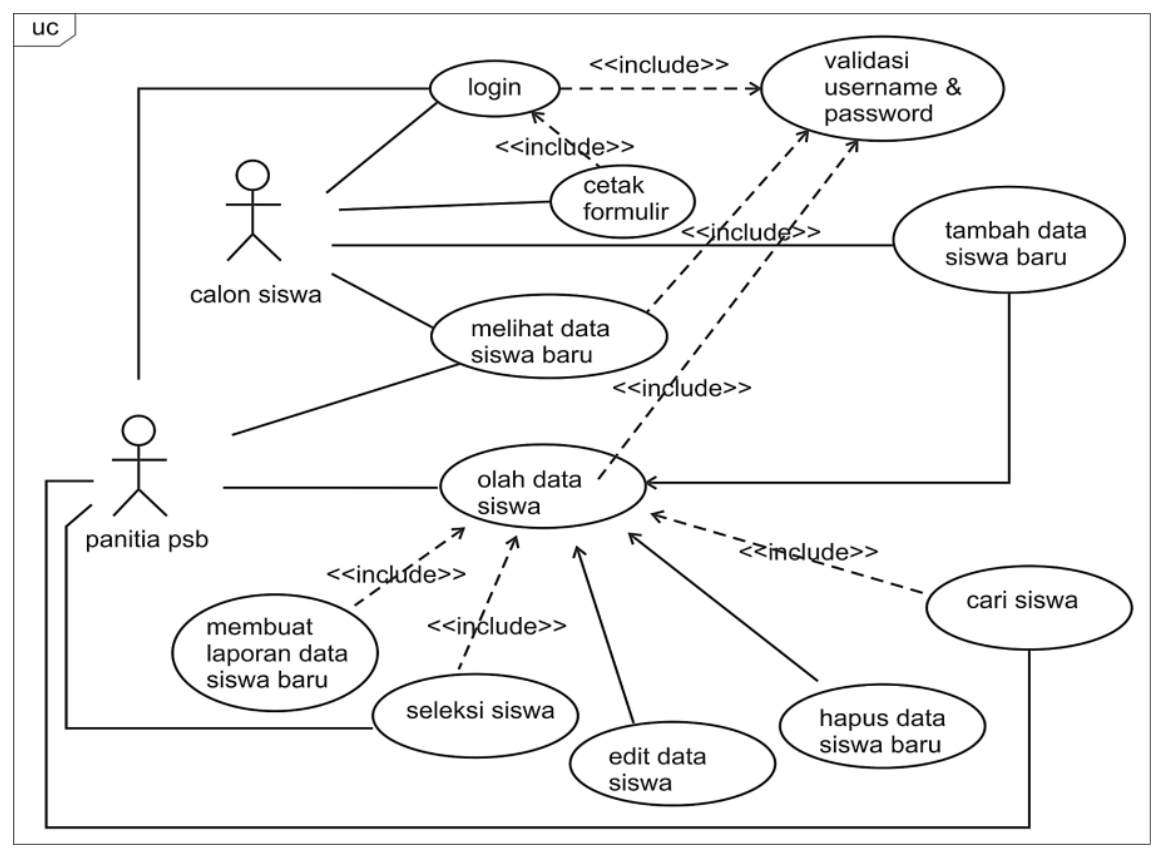

Gambar 3. Usecase Diagram Pendaftaran Siswa 


\subsubsection{Class Diagram}

Sebuah class diagram menjelaskan tipe dari objek dalam sebuah sistem dan berbagai jenis hubungan yang terdapat diantara objek-objek tersebut. Berikut gambar:

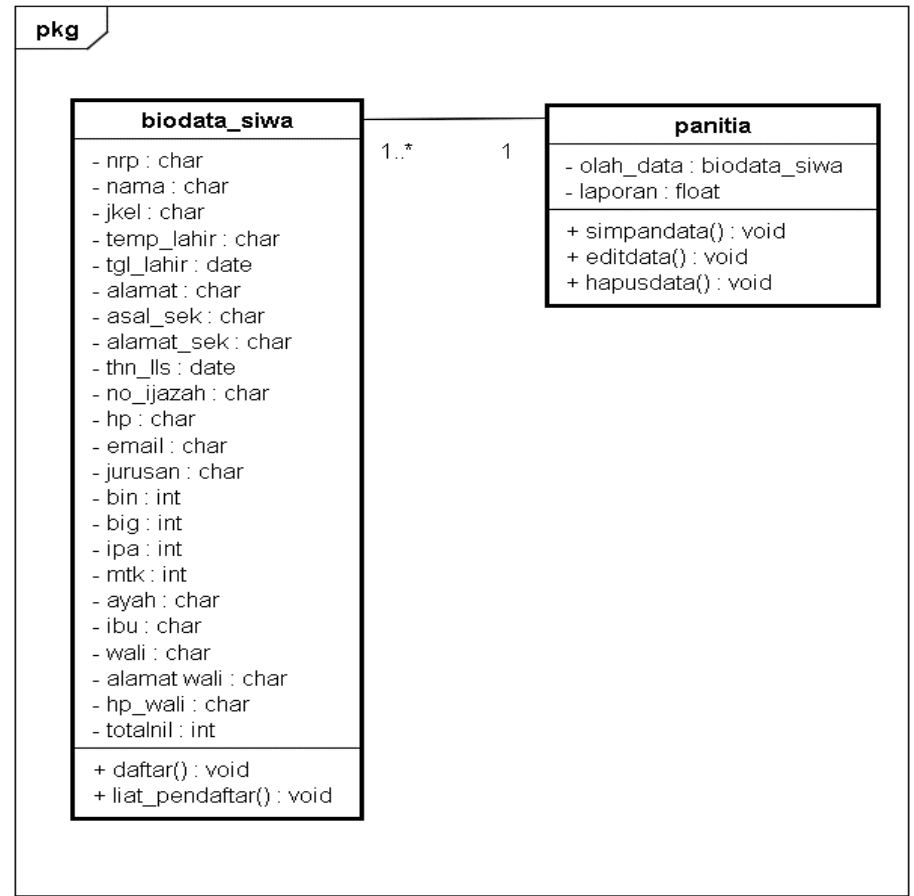

Gambar 4. Class Diagram

\subsection{Desain Sistem Menggunakan Metode Prototype}

\subsubsection{Desain Aliran Data}

\subsubsection{Diagram Konteks}

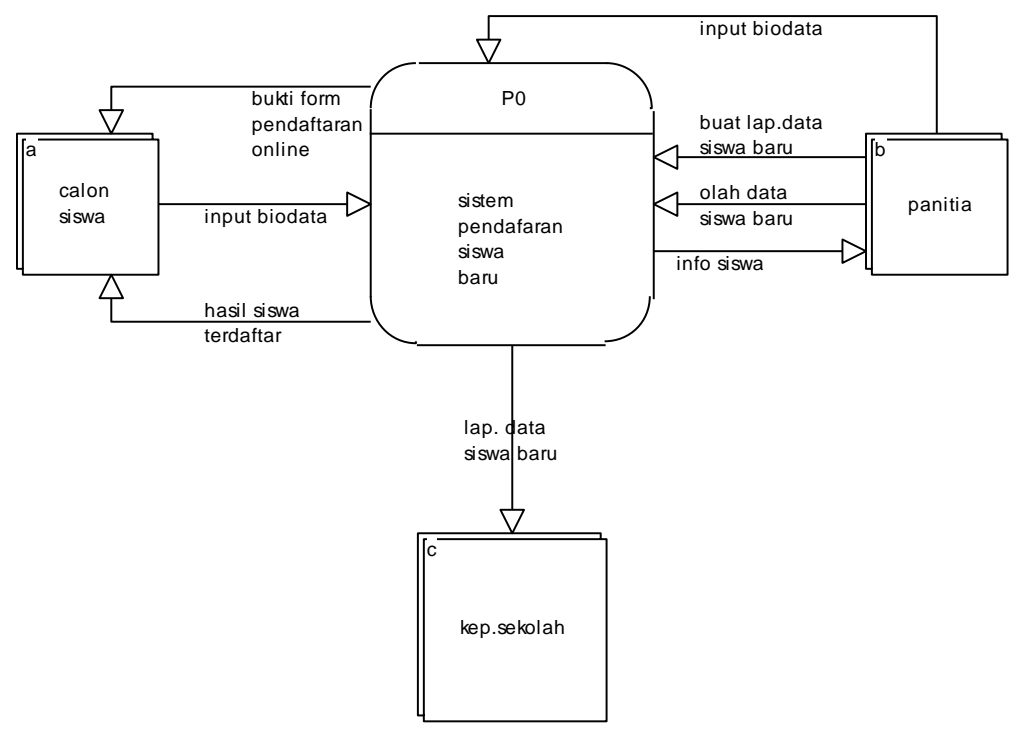

Gambar 5. Diagram Konteks Pendaftaran Siswa Baru 
Citec Journal, Vol. 2, No. 2, Februari 2015 - April 2015

\subsubsection{Data Flow Diagram Level 0}

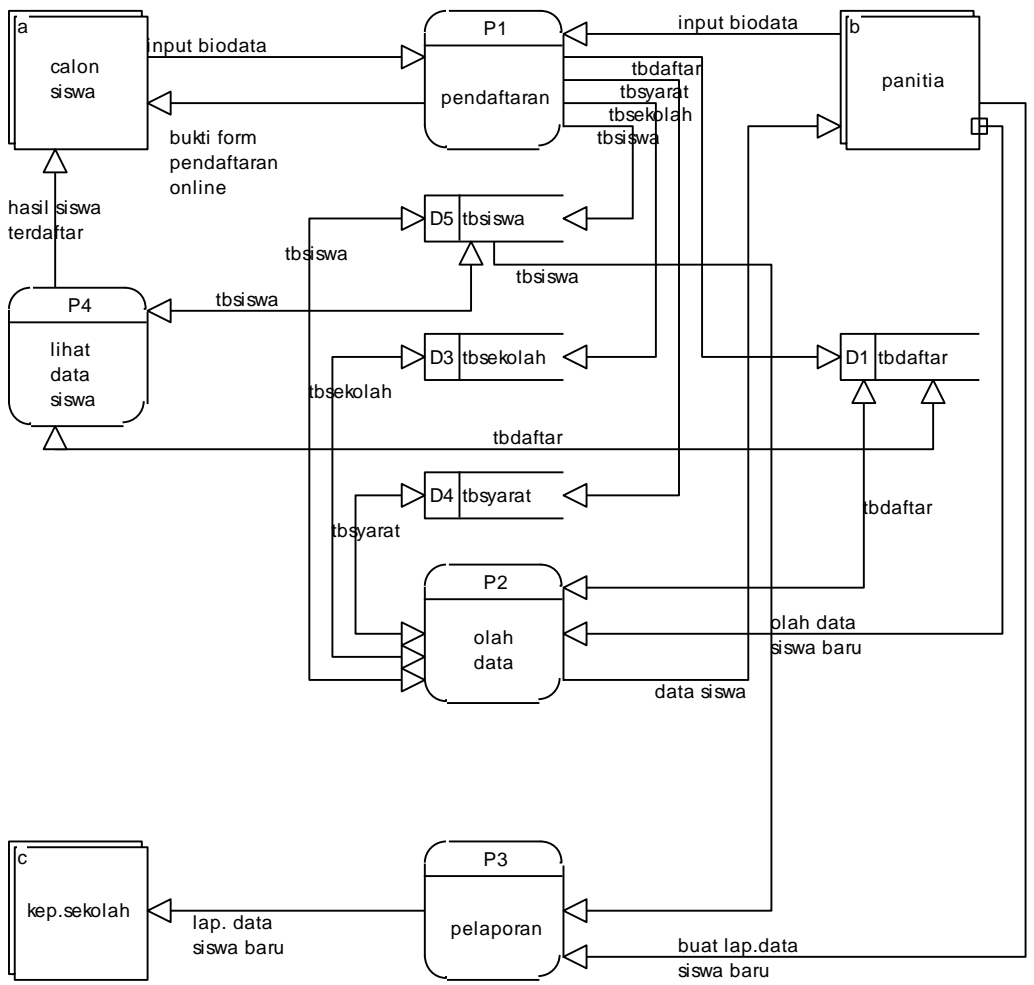

Gambar 6. Data Flow Diagram level 0

\subsubsection{Data Flow Diagram Level 0 Proses 2}

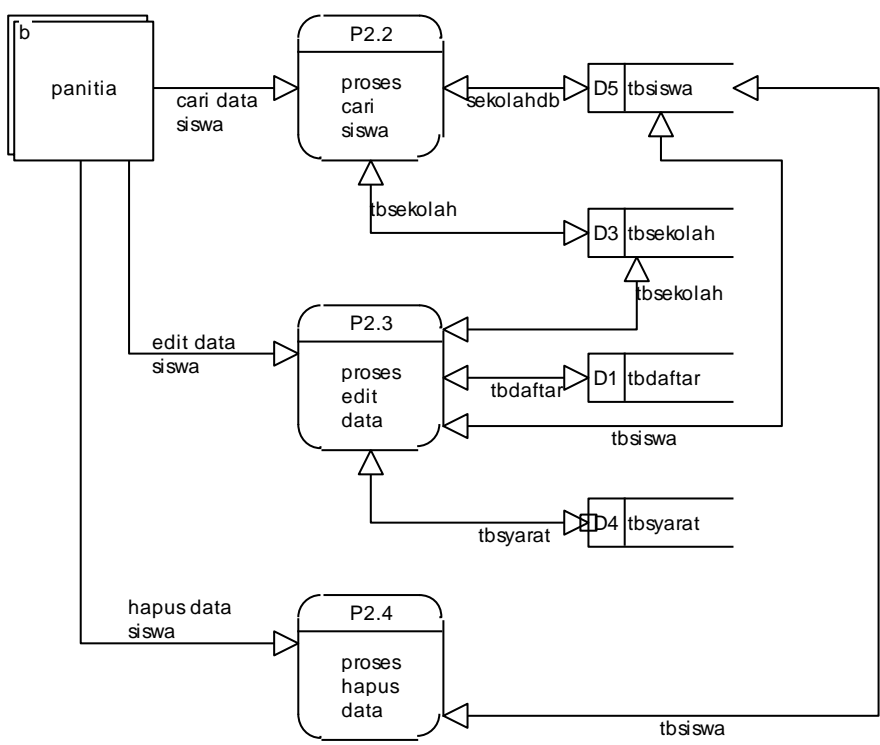

Gambar 7. Data Flow Diagram level 0 proses 2 
Berdasarkan desain perancangan RUP dan Prototype yang diuraikan diatas maka penulis dapat membandingkan masing-masing tahapan dari metode yang dipakai sebagai berikut:

Tabel 1. Uraian Perbandingan Metode

\begin{tabular}{|c|c|c|}
\hline NO & RUP & PROTOTYPE \\
\hline 1. & $\begin{array}{l}\text { Inception (Permulaan) } \\
\text { Pada tahap ini pengembang mendefinisikan } \\
\text { batasan kegiatan seperti pembuatan aplikasi } \\
\text { hanya mencakup kebutuhan sumber daya } \\
\text { manusia yang terlibat, pendaftaran dan } \\
\text { pengolahan data siswa yang mendaftar, } \\
\text { kemudian pengembang melakukan analisis } \\
\text { kebutuhan end user seperti form form yang } \\
\text { dibutuhkan dalam pendaftaran siswa, dan } \\
\text { melakukan perancangan awal perangkat } \\
\text { lunak dengan perancangan arsitektural dan } \\
\text { usecase seperti pada gambar } 3.1 \text { usecase } \\
\text { pendaftaran siswa baru. Ruang lingkup } \\
\text { sistem secara memadai sebagai dasar untuk } \\
\text { mengesahkan biaya awal dan anggaran. } \\
\text { Peran usecase pada tahap ini adalah: } \\
\text { a. menolong mengembangkan scope } \\
\text { proyek penbuatan perangkat lunak } \\
\text { b. menolong menetapkan penjadwalan dan } \\
\text { anggaran }\end{array}$ & $\begin{array}{l}\text { Pengumpulan Kebutuhan } \\
\text { Pihak sekolah / end user dan pengembang } \\
\text { bersama-sama mendefinisikan format } \\
\text { seluruh perangkat lunak, mengiden- } \\
\text { tifikasikan semua kebutuhan end user, } \\
\text { dan garis besar sistem yang akan dibuat, } \\
\text { seperti : } \\
\text { a. pembuatan aplikasi memfasilitasi } \\
\text { penerimaan siswa baru } \\
\text { b. pengolahan data siswa baru } \\
\text { c. output data untuk siswa (bukti form } \\
\text { pendaftaran) dan user (lap. siswa } \\
\text { terdaftar) } \\
\text { d. aplikasi bisa diakses kapan dan } \\
\text { dimana saja } \\
\text { e. desain tampilan web } \\
\text { f. sumber daya manusia yang terlibat } \\
\text { langsung dalam penerimaan siswa } \\
\text { baru }\end{array}$ \\
\hline 2. & $\begin{array}{l}\text { Elaboration ( Pemerincian ) } \\
\text { Pada tahap ini dilakukan perancangan } \\
\text { perangkat lunak mulai dari } \\
\text { menspesifikasikan fitur perangkat lunak } \\
\text { hingga perilisan prototipe versi beta dari } \\
\text { perangkat lunak/display menu awal web } \\
\text { yang akan dibangun dan menganalisanya } \\
\text { dari resiko dan berbagai persyaratan } \\
\text { kemudian menetapkan batasan-batasan pada } \\
\text { perancangan perangkat lunak. Adapun } \\
\text { analisa dan persyaratannya sebagai berikut: } \\
\text { a. Menggunakan model kasus di mana } \\
\text { penggunaan-kasus dan para pelaku seperti } \\
\text { pihak sekolah terkait, admin, calon siswa, } \\
\text { dan masyarakat telah diidentifikasi dan } \\
\text { sebagian besar kasus penggunaan } \\
\text { deskripsi dikembangkan. Kasus } \\
\text { penggunaan model ini harus menjadi } 80 \% \\
\text { lengkap. } \\
\text { b. Penjelasan tentang arsitektur perangkat } \\
\text { lunak dalam proses pengembangan sistem } \\
\text { perangkat lunak penerimaan siswa baru. } \\
\text { Peran usecase pada tahap ini adalah: } \\
\text { 1) Menolong dalam menganalisa resiko } \\
\text { 2) Menolong mempersiapkan fase } \\
\text { berikutnya yaitu kontruksi }\end{array}$ & $\begin{array}{l}\text { Membangun Prototyping } \\
\text { Membangun prototyping dengan } \\
\text { membuat perancangan sementara yang } \\
\text { berpusat pada penyajian kepada user, } \\
\text { seperti pada gambar 3.3 diagram konteks } \\
\text { pendaftaran siswa. Dengan prototyping, } \\
\text { pengembang membangun semacam } \\
\text { sistem uji coba, tanpa harus } \\
\text { menggunakan data aktual sekolah dan } \\
\text { tidak harus 100\% sama dengan sistem } \\
\text { aktual yang akan diimplementasikan. } \\
\text { Karena dibangun secara bertahap dengan } \\
\text { cara uji coba maka pembuatan prototype } \\
\text { akan memakan waktu lebih sedikit jika } \\
\text { dibandingkan harus langsung membuat } \\
\text { sistem final yang langsung siap jalan. } \\
\text { Evaluasi Prototyping } \\
\text { Evaluasi ini dilakukan oleh pihak } \\
\text { sekolah/end user apakah prototyping } \\
\text { yang sudah dibangun sudah sesuai } \\
\text { dengan keinginan end user. Jika sudah } \\
\text { sesuai maka langkah keempat akan } \\
\text { diambil. Jika tidak, maka prototyping } \\
\text { diperbaiki dengan mengulang langkah } 1 \text {, } \\
2 \text { dan 3. }\end{array}$ \\
\hline
\end{tabular}


Tabel 1 (lanjutan)

\begin{tabular}{|c|c|c|}
\hline NO & RUP & PROTOTYPE \\
\hline 3. & $\begin{array}{l}\text { Construction (Kontruksi) } \\
\text { Pengimplementasian rancangan perangkat } \\
\text { lunak yang telah dibuat dilakukan pada } \\
\text { tahap ini. Pada akhir tahap ini, perangkat } \\
\text { lunak versi akhir yang sudah disetujui } \\
\text { administrator dirilis beserta dokumentasi } \\
\text { perangkat lunak kemudian melakukan } \\
\text { sederatan iterasi yang mana setiap iterasi } \\
\text { juga melibatkan proses-proses seperti } \\
\text { analisa teknologi yang akan digunakan, } \\
\text { desain, implementasi, coding menggunakan } \\
\text { bahasa pemrogaman php, iterasi dilakukan } \\
\text { tidak serempak tapi secara berulang ulang } \\
\text { dengan beberapa penambahan disetiap } \\
\text { pengulangannya. } \\
\text { Peran usecase pada tahap ini adalah : } \\
\text { a. Melakukan sederetan iterasi } \\
\text { b. Pada setiap iterasi akan melibatkan } \\
\text { proses berikut: analisa desain, } \\
\text { implementasi dan testing } \\
\text { c. Memimalisir resiko teknik }\end{array}$ & $\begin{array}{l}\text { Mengkodekan Sistem } \\
\text { Dalam tahap ini prototyping yang sudah } \\
\text { disepakati diterjemahkan ke dalam } \\
\text { bahasa pemrograman PHP. } \\
\text { Menguji Sistem } \\
\text { Setelah sistem sudah menjadi suatu } \\
\text { perangkat lunak yang siap pakai, sistem } \\
\text { akan diuji dan disesuaikan dengan } \\
\text { kebutuhan aplikasi untuk penerimaan } \\
\text { siswa baru. Pengujian ini dilakukan } \\
\text { dengan pegujian Blackbox, pengujian } \\
\text { arsitektur dan lain-lain. Karena sifatnya } \\
\text { yang bersifat uji-coba, mempersiapkan } \\
\text { prototype membutuhkan waktu lebih } \\
\text { singkat daripada mempersiapkan sistem } \\
\text { yang siap launcing. } \\
\text { Evaluasi System } \\
\text { End user mengevaluasi apakah sistem } \\
\text { yang sudah jadi sudah sesuai dengan yang } \\
\text { diharapkan. Jika sudah, maka langkah } \\
\text { ketujuh dilakukan, jika belum maka } \\
\text { mengulangi langkah } 4 \text { dan 5. }\end{array}$ \\
\hline 4. & $\begin{array}{l}\text { Transition (Transisi) } \\
\text { Instalasi, deployment dan sosialisasi } \\
\text { perangkat lunak dilakukan pada tahap ini } \\
\text { dimana penyerahan perangkat lunak kepada } \\
\text { user, kemudian mengujinya di tempat user, } \\
\text { dan memperbaiki masalah-masalah yang } \\
\text { muncul saat dan setelah pengujian. } \\
\text { Peran usecase pada tahap ini adalah: } \\
\text { a. Membuat apa yang sudah dimodelkan } \\
\text { menjadi suatu produk jadi } \\
\text { b. Dalam fase ini dilakukan: } \\
\text { 1) Beta dan performance testing } \\
\text { 2) Membuat dokumentasi tambahan } \\
\text { seperti; training, user guides dan } \\
\text { sales kit }\end{array}$ & $\begin{array}{l}\text { Menggunakan Sistem } \\
\text { Perangkat lunak yang telah diuji dan } \\
\text { diterima end user siap untuk digunakan. }\end{array}$ \\
\hline
\end{tabular}


Tabel 2. Perbandingan Kelebihan dan Kekurangan Metode

\begin{tabular}{|c|c|c|}
\hline METODE & KELEBIHAN & KEKURANGAN \\
\hline RUP & $\begin{array}{l}\text { 1. Menyediakan akses yang mudah } \\
\text { terhadap pengetahuan dasar bagi } \\
\text { anggota tim. } \\
\text { 2. Menyediakan petunjuk bagaimana } \\
\text { menggunakan uml secara efektif. } \\
\text { 3. Mendukung proses pengulangan } \\
\text { dalam pengembangan software. } \\
\text { 4. Memungkinkan adanya penambahan- } \\
\text { penambahan pada proses. } \\
\text { 5. Memungkinkan untuk secara } \\
\text { sistematis mengontrol perubahan- } \\
\text { perubahan yang terjadi pada software } \\
\text { selama proses pengembangannya. } \\
\text { 6. Memungkinkan untuk menjalankan } \\
\text { test }\end{array}$ & $\begin{array}{l}\text { 1. Metodologi ini hanya dapat } \\
\text { digunakan pada pengembangan } \\
\text { perangkat lunak yang } \\
\text { berorientasi objek dengan } \\
\text { berfokus pada uml (unified } \\
\text { modeling language). } \\
\text { 2. Membutuhkan waktu yang } \\
\text { cukup lama dibandingkan } \\
\text { metode lain }\end{array}$ \\
\hline Proto & $\begin{array}{l}\text { 1. Prototype melibatkan user dalam } \\
\text { analisa dan desain. } \\
\text { 2. Punya kemampuan menangkap } \\
\text { requirement secara konkret daripada } \\
\text { secara abstrak } \\
\text { 3. Untuk digunakan secara standalone } \\
\text { 4. Digunakan untuk memperluas sdlc } \\
\text { 5. Mempersingkat waktu pengembangan } \\
\text { sistem informasi. }\end{array}$ & 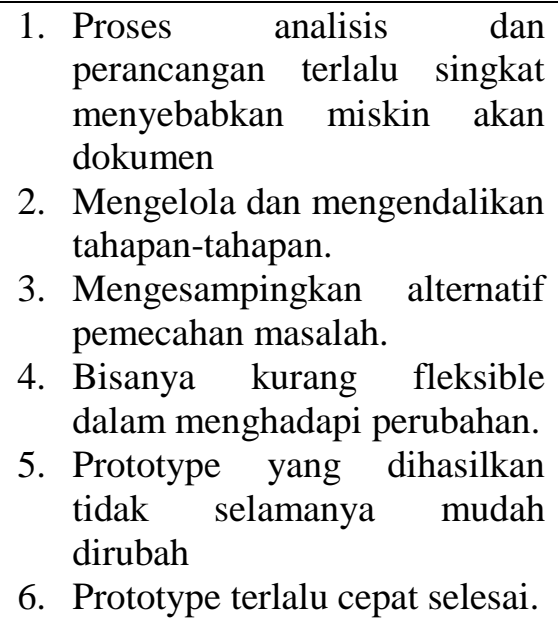 \\
\hline
\end{tabular}

\subsection{Analisis Perbandingan}

\subsubsection{Metode RUP}

Menurut tabel 1 dan tabel 2 maka dapat disimpulkan kelebihan dan kekurangan metode RUP adalah:

a. Spesifikasi kebutuhan dan kontrol sumber daya

Pengembang dan end user bersama-sama mendefinisikan seluruh spesifikasi kebutuhan yang akan ada dalam aplikasi penerimaan siswa baru, dan mengontrol seluruh sumber daya yang dibutuhkan dalam menentukan ruang lingkup penerimaan siswa baru secara online

b. Biaya yang dikeluarkan

Kebutuhan biaya dalam pengembangan aplikasi penerimaan siswa baru memerlukan biaya lebih banyak seperti biaya penyewaan domain, biaya perawatan aplikasi, pembukuan dokumentasi dan lain sebagainya karena aplikasi yang dibuat sudah memenuhi kebutuhan end user dan telah siap untuk diimplementasikan

c. Waktu yang dibutuhkan

Karena aplikasi yang dibuat sudah siap digunakan maka membutuhkan waktu yang lebih lama untuk menganalisa resiko dan proses pengembangan yang lebih sempurna kemudian menguji secara berulang untuk menghindari resiko keamanan 
d. Analisa resiko dan dokumentasi

Analisa mendalam dari masing masing tim pengembang yang didokumentasikan dengan tool perancangan UML yang lebih terperinci dan lengkap dari tiap tahap sehingga end user lebih mengetahui sistem yang dibangun dan meminimalisir resiko baik dalam resiko keamanan aplikasi, kelangsungan hidup sistem, human erorr, resiko kesalahan server domain, sehingga mudah dikembangkan lagi jika ada penambahan atau perubahan dimasa yang akan datang.

\subsubsection{Metode Prototype}

Kelebihan dan kekurangan metode Prototype menurut tabel 1 dan tabel 2 adalah:

a. Spesifikasi kebutuhan dan kontrol sumber daya

Dengan prototyping, user akan terus terlibat langsung dengan pengembang, pengembang membangun semacam sistem uji coba, tanpa harus menggunakan data aktual dari end user dan tidak harus $100 \%$ sama dengan sistem aktual yang akan diimplementasikan. Karena dibangun secara bertahap dengan cara uji coba maka pembuatan prototype akan memakan waktu lebih sedikit jika dibandingkan harus langsung membuat sistem final yang langsung siap jalan.

b. Biaya yang dikeluarkan

Pembuatan prototype membutuhkan biaya lebih sedikit daripada langsung mengembangkan sistem secara keseluruhan tanpa menggunakan prototype. Hal ini dikarenakan prototype masih bersifat uji coba dan belum sepenuhnya siap berjalan. Prototype masih membutuhkan saran-saran dan masukan dari pengguna sistem sebelum dikembangkan menjadi aplikasi penerimaan siswa baru yang final dan siap diimplementasikan.

c. Waktu yang dibutuhkan

Karena sifatnya yang bersifat uji-coba, mempersiapkan prototype membutuhkan waktu lebih singkat daripada mempersiapkan sistem yang siap launching. Apabila tidak menggunakan prototyping, kesalahan dan kekurangan sistem baru akan diketahui setelah sistem siap dijalankan. Tentunya memperbaiki kesalahan saat sistem telah final akan memakan waktu dan biaya lebih besar.

d. Analisa resiko dan dokumentasi

Analisa resiko pengembangan yang lebih mengacu pada awal tahap kebutuhan dan hanya fokus pada penyajian awal dengan tool perancangan menggunakan flowchart, diagram alir dokumen yang memberikan gambaran secara garis besar dari sistem penerimaan siswa baru sehingga bila ada penambahan atau perubahan akan mengalami kesulitan dan keterabatasan pengembangan aplikasi. Dokumentasi yang dihasilkan kurang memadai untuk digunakan sebagai pedoman sosialisai penggunaan aplikasi penerimaan siswa baru.

Tabel 3. Analisis Perbandingan Model

\begin{tabular}{|l|l|l|}
\hline \multicolumn{1}{|c|}{ FEATURE/MODEL } & \multicolumn{1}{c|}{ RUP } & \multicolumn{1}{c|}{ PROTOTYPE } \\
\hline Spesifikasi kebutuhan & Ada di awal tahap & Ada di awal tahap \\
\hline Kontrol sumber daya & Ada & Ada \\
\hline Analisa resiko & Selalu ada & Hanya ada diawal \\
\hline Keterlibatan resiko & Resiko penting pada tahap awal & Rendah \\
\hline Sumber daya manusia & Lebih banyak & Sedikit \\
\hline Keterlibatan user & Hanya ada pada awal \& fase terakhir & Selalu ada \\
\hline Waktu & Lebih lama & Singkat \\
\hline Biaya & Lebih mahal & Murah \\
\hline Pengembangan & Mudah dikembangkan & Terbatas \\
\hline Keamanan & Sangat penting & Lemah \\
\hline Dokumentasi \& training user & Lengkap & Kurang \\
\hline Tool Perancangan & UML & DFD \\
\hline
\end{tabular}




\subsection{Relasi Antar Tabel}

Tabel yang digunakan pada aplikasi penerimaan siswa baru berjumlah 4 yaitu tabel siswa, tabel asal_sek, tabel daftar dan tabel syarat. Relasi antar tabel ini dapat dilihat pada gambar 8 .

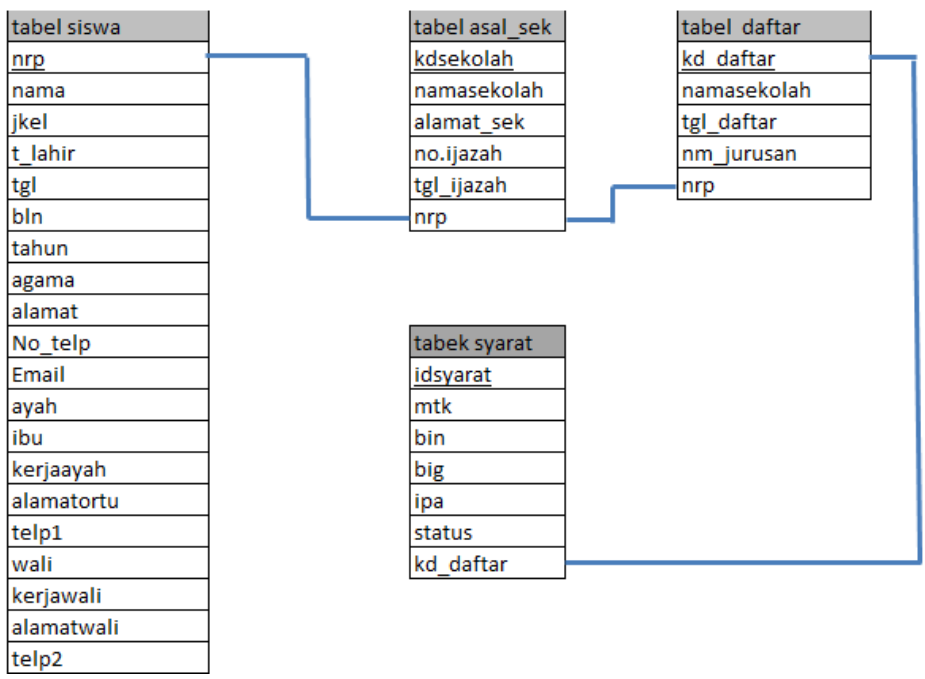

Gambar 8. Relasi Antar Tabel

\subsection{Perancangan Antarmuka Pengguna (User Interface)}

\subsubsection{Form Pendaftaran Siswa}

Form ini digunakan untuk calon siswa yang ingin mendaftar.

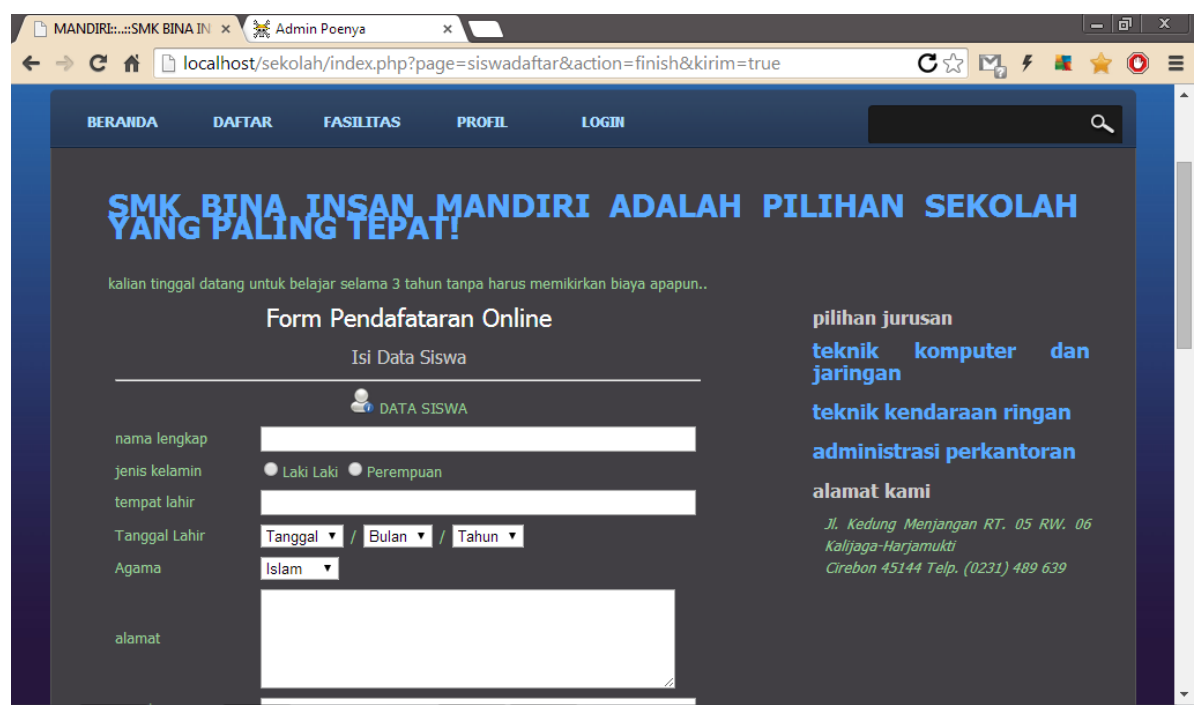

Gambar 9. Halaman Input Data Siswa 
Citec Journal, Vol. 2, No. 2, Februari 2015 - April 2015

ISSN: 2354-5771

\subsubsection{Form Informasi Hasil dan Cetak}

Form ini digunakan untuk melihat hasil penerimaan siswa yang telah mendaftar.

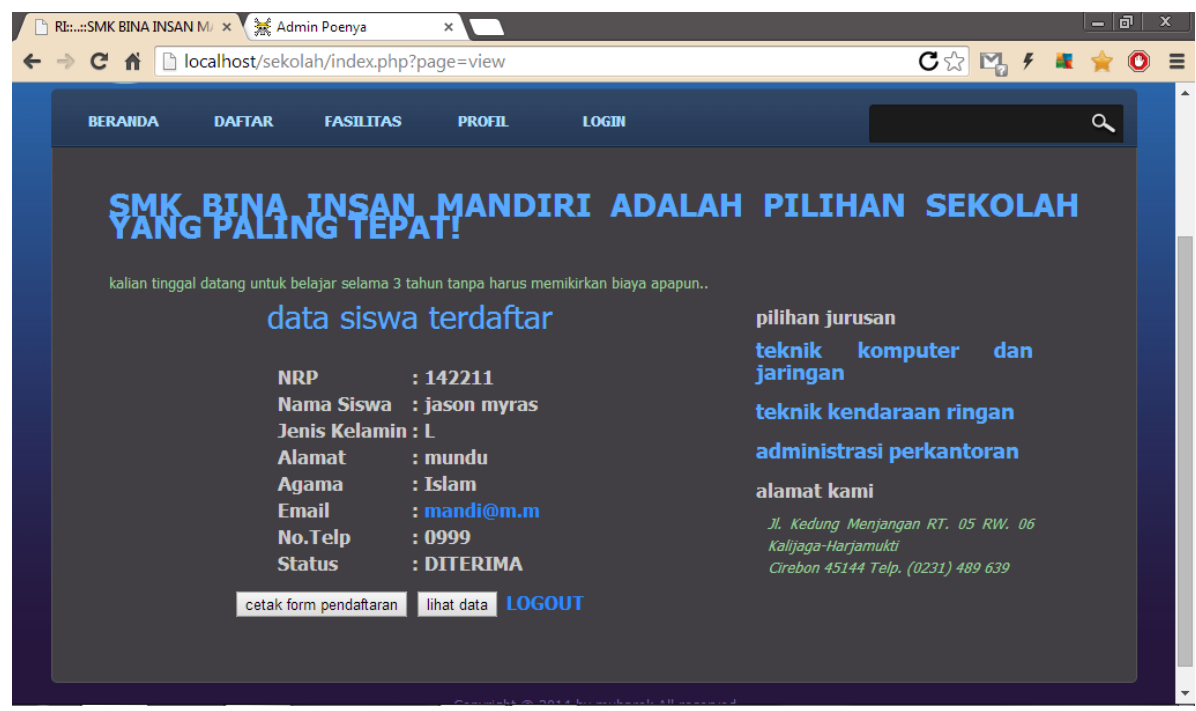

Gambar 10. Form Hasil Pendaftaran

\subsubsection{Form Bukti Pendaftaran}

Form ini digunakan untuk bukti pendaftaran siswa secara online.

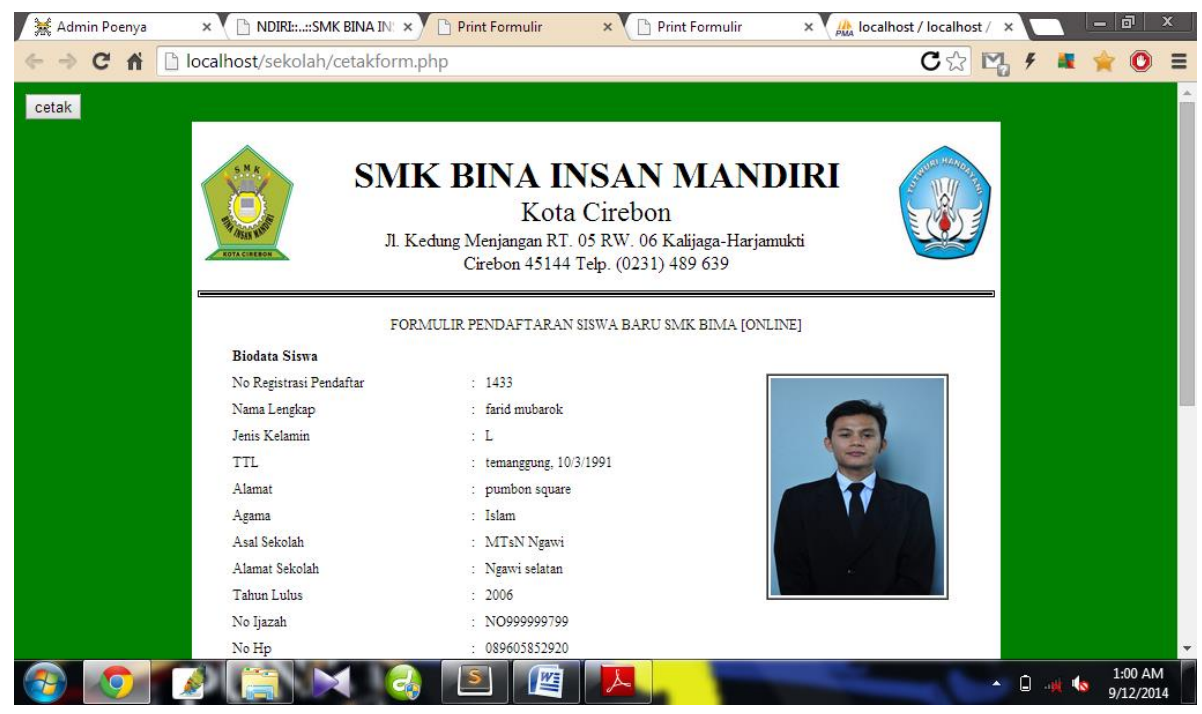

Gambar 11. Form Pendaftaran Online 


\section{KESIMPULAN}

Berdasarkan hasil penelitian dan uji coba yang telah dilakukan dalam penelitian ini, maka dapat ditarik beberapa kesimpulan yaitu:

1. Dengan adanya sistem informasi penerimaan siswa baru secara online, akan mempermudah para calon siswa untuk mendaftar dan melihat hasil kelulusan masuk sekolah tanpa datang langsung kesekolah.

2. Dengan adanya sistem informasi penerimaan siswa baru secara online, dapat mempermudah mengolah data yang awalnya manual menjadi terkomputerisasi.

3. Dengan adanya sistem informasi penerimaan siswa baru secara online, dapat memberikan informasi yang realtime.

4. Metodologi RUP sangat cocok digunakan pada pengembangan perangkat lunak berorientasi objek. Rational Unified Process mengadopsi Object Oriented Programming (OOP) karena memisahkan operasi-operasi maupun komponen yang terlibat di dalamnya ke dalam sebuah objek-objek yang berbeda dan merupakan suatu produk proses yang membawa sangat banyak pengetahuan, selalu terbaru, dan dalam wujud "e-coach" atau pelatih elektronik.

5. Metode pengembangan perangkat lunak model RUP dirancang agar dapat menerima perubahan-perubahan dalam rangka menyempurnakan prototype yang sudah ada sehingga pada akhirnya dapat menghasilkan perangkat lunak yang dapat diterima dan perubahanperubahan yang terjadi dapat dianggap merupakan bagian dari proses pengembangan itu sendiri.

6. Semua model pengembangan perangkat lunak yang berbeda memiliki kelebihan dan kekurangan mereka sendiri. Namun demikian, dalam dunia pengembangan perangkat lunak komersial kontemporer, fusi semua metodologi ini dimasukkan. Waktu sangat penting dalam pengembangan perangkat lunak. Jika penundaan terjadi dalam tahap pengembangan, itu dapat mempengaruhi reputasi perusahaan pengembang.

\section{SARAN}

Setelah dilakukan penelitian ini, penulis mempunyai saran-saran sebagai berikut:

1. Diharapkan untuk penelitian selanjutnya dapat mengkombinasikan sistem akademik sekolah yang lebih lengkap.

2. Diharapkan bagi pihak sekolah untuk bisa mengaplikasikan progam kedalam proses penerimaan siswa baru yang akan datang

\section{DAFTAR PUSTAKA}

[1] Rosa, Salahuddin, M., 2013, Rekayasa Perangkat Lunak Terstruktur dan Berorientasi Object, Informatika, Bandung

[2] Guritno, S., Sudaryono, Rahardja, U., 2011, Theory and Application of IT Research: Metodologi Penelitian Teknologi Informasi, Andi Offset, Yogyakarta.

[3] Gunawan, A., Gunawan, B., Honggo, H., 2011, Analisis dan Perancangan Sistem Informasi Manufaktur pada PG Mitra Palembang, Skripsi, Jurusan Sistem Informasi, STMIK GI MDP.

[4] Permatasari, D., 2010, Perancangan Sistem Informasi Akademik Di SMK Pasundan Majalaya Berbasis Web, Skripsi, Program Studi Sistem Informasi, Fakultas Teknik dan Ilmu Komputer, Universitas Komputer Indonesia, Bandung.

[5] Kartikadarma, E., Ihwati, U., 2011, Desain Alat Bantu Konfigurasi Router Berbasis Gui (Cisco Router Dictionary), Journal Techno COM, Vol 10, No, 2, Hal 41-48. 
Citec Journal, Vol. 2, No. 2, Februari 2015 - April 2015

ISSN: 2354-5771

[6] Sabale, R. G., Dani, A. R., 2012, Comparative Study of Prototype Model For Software Engineering With System Development Life Cycle, IOSR Journal of Engineering (IOSRJEN), Vol 2, No 7, Hal 21-24.

[7] Mujumdar, A., Masiwal, G., Chawan, P. M., 2012, Analysis of Various Software Process Models, International Journal of Engineering Research and Application (IJERA), Vol 2, No 3, Hal 2015-2021.

[8] Jogiyanto, 2010, Analisis dan Desain "Pendekatan Tersetrktur Teori dan praktik Aplikasi Bisnis", Andi Offset, Yogyakarta.

[9] Fathansyah, 2012, Basis Data, Informatika, Bandung.

[10] Sutabri, T., 2010, Analisa Sistem Informasi, Andi Offset, Yogyakarta.

[11] Bell, C., 2012, Expert MySQL, Appres, New York.

[12] Aditama, R., 2013, Sistem Akademik Kampus Berbasis Web Dengan PHP, Lokomedia, Yogyakarta.

[13] O’Brien, J., Marakas, G., 2011, Management Information System Tenth Edition, Mc. GrawHill Companies, New York.

[14] Febrianto, A., 2010, Prototyping, http://wartawarga.gunadarma.ac.id/2010/03/prototyping.html?zx=7644bfe536c482ce, diakses tanggal 23 Agustus 2014 